\title{
Heat Transfer and Entropy Generation of Non-Newtonian Laminar Flow in Microchannels with Four Flow Control Structures
}

\author{
Ke Yang ${ }^{1}$, Di Zhang ${ }^{1, *}$, Yonghui Xie ${ }^{2}$ and Gongnan Xie ${ }^{3}$ \\ 1 Key Laboratory of Thermal-Fluid Science and Engineering, Ministry of Education, Xi'an Jiaotong University, \\ Xi'an 710049, China; snr.sk@stu.xjtu.edu.cn \\ 2 School of Energy and Power Engineering, Xi'an Jiaotong University, Xi'an 710049, China; \\ yhxie@mail.xjtu.edu.cn \\ 3 Department of Mechanical and Power Engineering, School of Marine Science and Technology, \\ Northwestern Polytechnical University, Xi'an 710072, China; gongnan.xie@gmail.com \\ * Correspondence: zhang_di@mail.xjtu.edu.cn; Tel.: +86-29-8266-6559
}

Academic Editor: Brian Agnew

Received: 28 June 2016; Accepted: 8 August 2016; Published: 12 August 2016

\begin{abstract}
Flow characteristics and heat transfer performances of carboxymethyl cellulose (CMC) aqueous solutions in the microchannels with flow control structures were investigated in this study. The researches were carried out with various flow rates and concentrations of the CMC aqueous solutions. The results reveal that the pin-finned microchannel has the most uniform temperature distribution on the structured walls, and the average temperature on the structured wall reaches the minimum value in cylinder-ribbed microchannels at the same flow rate and CMC concentration. Moreover, the protruded microchannel obtains the minimum relative Fanning friction factor $f / f_{0}$, while, the maximum $f / f_{0}$ is observed in the cylinder-ribbed microchannel. Furthermore, the minimum $f / f_{0}$ is reached at the cases with CMC2000, and also, the relative Nusselt number $\mathrm{Nu} / \mathrm{Nu} u_{0}$ of CMC2000 cases is larger than that of other cases in the four structured microchannels. Therefore, $2000 \mathrm{ppm}$ is the recommended concentration of CMC aqueous solutions in all the cases with different flow rates and flow control structures. Pin-finned microchannels are preferred in low flow rate cases, while, $\mathrm{V}$-grooved microchannels have the minimum relative entropy generation $S^{\prime} / S_{0}{ }^{\prime}$ and best thermal performance TP at CMC2000 in high flow rates.
\end{abstract}

Keywords: non-Newtonian fluid; laminar heat transfer; entropy generation; flow control structures

\section{Introduction}

In microtechnology a microchannel is defined as a channel with a hydraulic diameter smaller than $1 \mathrm{~mm}$ [1]. As the heat flux densities increases in the automotive, aerospace, air separation, integrated circuit, biological, power engineering, chemical engineering and cryogenic industries, the heat transfer of fluid flow in the microfluidic devices has gained tremendous attention and the requirement of a flow control structure with large heat removal and lower pressure penalty has become more urgent in recent years. In order to enhance the thermal performance of the fluid flow in the channel, many different flow control structures has been proposed, such as dimples/protrusions [2,3], corrugated plates [4], pin-fins [5-7], inner V-grooves, ribs, wavy surfaces [8] etc., and even combined with curved channels $[9,10]$. In these different flow control structures, protrusions, pin-fins, cylinder-ribs, and V-grooves are the four most basic structures. Moreover, the non-Newtonian power-law fluid, with its varied dynamic viscosity due to the shear rate in the flow domain, has many different heat transfer and fluid flow characteristics when compared with Newtonian fluid, and the shear-thinning power 
law fluid, in particular, has some advantages in reducing flow resistance combined with flow control structures according to Li's research [3], for example.

Investigations have studied separately many different aspects of fluid flow and heat transfer characteristics in different channels. Xie et al. [11] studied the heat transfer in channels with protrusions, and the results shows that protrusion structures can effectively enhance the heat and mass transfer of carboxymethyl cellulose (CMC) solutions with low penalty in specific cases. Naphon and Kornkumjayrit [4] analysed the two dimensional fluid flow and heat transfer in a channel with a V-shaped plate under constant heat flux conditions, and found that the corrugated surface has a significant effect on the enhancement of heat transfer. Roth et al. [12] evaluated the heat transfer in straight silicon microchannels with integrated in-line and staggered pin-fin arrays at clearance to diameter ratios of $0.50-0.77$ in the laminar flow regime at Reynolds numbers ranging from 9 to 246 . The measurements showed that a significant portion of the fluid flows below the pin fins in the clearance bypass region, leading to heat transfer results that show an improvement over an unfinned reference geometry. Li and Wang et al. [13] investigated the 3-dimensional flow development in curved rectangular ducts with continuously varying curvature using Particle Image Velocimetry (PIV) and numerical simulations, and the results revealed complex changes in the flow pattern with respect to both the flow and geometric parameters. All these studies show that flow control structures can effectively enhance or influence heat transfer in microchannels.

On the other hand, investigations about fluid flow and heat transfer of non-Newtonian fluids [14] have been conducted widely. Barkhordari and Etemad [15] investigated the slip flow and thermal fields of shear-thinning fluids in microchannels. The increasing slip coefficient resulted in an increase of the local Nusselt number, and this effect was enhanced as the power law index increased. Peixinho et al. [16] experimentally studied the forced convection heat transfer of non-Newtonian flow in transitional periodic pipes. The results showed that the non-Newtonian behavior stabilized the flow, so the critical Reynolds number increased with shear-thinning. Ternik [17] investigated the effects of the generalized Newtonian fluids on the threshold of the transition from flow symmetry to its asymmetry for the flow through a planar sudden expansion, the results showed the pressure gradient and flow resistance increased compared with Newtonian fluids, also, the vortices' length was greatly affected by the shear-thinning behavior. Manica and De Bortoli [18] found that the critical Reynolds number, when recirculation occurred, was lower for a shear-thinning power-law fluid than that for a Newtonian fluid. So non-Newtonian power law shear-thinning fluids with proper characteristics are another factor that has great influence on heat transfer and flow resistance. Ellahi et al. studied the generalized Couette flow of an Eyring-Powell fluid [19] and unsteady impressible flow of non-Newtonian micropolar fluid [20], whereby the physical problem of a micropolar fluid through a composite stenosis in an artery with permeable walls was first modelled and then simplified by using non-dimensional variables, thus obtaining many useful results. Nadeem and Sadaf [21] analysed two dimensional flow of a viscous nanofluid in an annulus with ciliated tips. The results show that the velocity profile increases near the endoscopic tube with increasing value of the Grashof number. Nitiapiruk and Mahian [22] experimentally investigated the performance characteristics of a $\mathrm{TiO}_{2} /$ water nanofluid in a microchannel using different thermophysical models, and concluded that the use of the model which is based on experimental data is very important to estimate the friction factor.

The previous literatures show that enhanced heat transfer with low pressure penalty can be expected by means of the combination of microchannel heat sinks with different flow control structures and shear-thinning power law fluids. Thus, more work should be doing to get detailed heat transfer and flow characteristics in microchannels with different flow control structures and different CMC concentrations, and then obtain an optimized flow control structure for a specific CMC concentration. Therefore, in what follows, the heat transfer and flow characteristics of CMC aqueous solutions of different concentration in microchanneld with four flow control structures under various flow rated are analyzed in detail. 


\section{Solution Method}

In a present study the fluid flow was assumed to be laminar and incompressible. The working substances are typical shear-thinning power law fluids.

\subsection{Governing Equations}

To describe the fluid flow in a microchannel, we need a continuity equation, momentum equationa, and to get the heat transfer performance, we also need an energy equation, so there are five equations if we consider a three-dimensional situation:

- Continuity equation:

$$
\frac{\partial U}{\partial x}+\frac{\partial V}{\partial y}+\frac{\partial W}{\partial z}=0
$$

- X-momentum equation:

$$
\rho\left(U \frac{\partial U}{\partial x}+V \frac{\partial U}{\partial y}+W \frac{\partial U}{\partial z}\right)=\frac{\partial \tau_{x x}}{\partial x}+\frac{\partial \tau_{y x}}{\partial y}+\frac{\partial \tau_{z x}}{\partial z}
$$

- Y-momentum equation:

$$
\rho\left(U \frac{\partial V}{\partial x}+V \frac{\partial V}{\partial y}+W \frac{\partial V}{\partial z}\right)=\frac{\partial \tau_{x y}}{\partial x}+\frac{\partial \tau_{y y}}{\partial y}+\frac{\partial \tau_{z y}}{\partial z}
$$

- Z-momentum equation:

$$
\rho\left(U \frac{\partial W}{\partial x}+V \frac{\partial W}{\partial y}+W \frac{\partial W}{\partial z}\right)=\frac{\partial \tau_{x z}}{\partial x}+\frac{\partial \tau_{y z}}{\partial y}+\frac{\partial \tau_{z z}}{\partial z}
$$

- Energy equation:

$$
\rho C_{p}\left(U \frac{\partial T}{\partial x}+V \frac{\partial T}{\partial y}+W \frac{\partial T}{\partial z}\right)=\lambda\left(\frac{\partial^{2} T}{\partial x^{2}}+\frac{\partial^{2} T}{\partial y^{2}}+\frac{\partial^{2} T}{\partial z^{2}}\right)
$$

where $U, V$ and $W$ are the velocity components in the $x, y, z$ directions, $T$ and $P$ are the temperature and pressure, respectively. $\rho$ denotes the fluid density, and it is a constant since we regard the working substances are incompressible. $\tau_{i j}$ is the viscous stress tensor, and subscripts $i$ and $j$ represent the normal direction of action surface and direction of stress component on the aforementioned surface, and it is just the same as the following equations if a shear-thinning power-law fluid is used as the working substances. Moreover, the pressure terms are additionally included in the normal stress tensors:

$$
\begin{gathered}
\tau_{i j}=\eta \varepsilon_{i j} \\
\varepsilon_{i j}=\frac{\partial u_{i}}{\partial x_{j}}+\frac{\partial u_{j}}{\partial x_{i}}
\end{gathered}
$$

where $\varepsilon_{i j}$ is the rate of deformation tensor, and $\eta$ is the viscosity, which is considered to be a function of the shear rate $\dot{\gamma}$, it can be computed by the following equations:

$$
\begin{gathered}
\eta=K \dot{\gamma}^{n-1} \\
\dot{\gamma}=\sqrt{\frac{1}{2}\left(\varepsilon_{i j}: \varepsilon_{i j}\right)}=\sqrt{\frac{1}{2} I_{2}}
\end{gathered}
$$




$$
\begin{gathered}
\frac{I_{2}}{2}=2\left(\frac{\partial U}{\partial x}\right)^{2}+2\left(\frac{\partial V}{\partial y}\right)^{2}+2\left(\frac{\partial W}{\partial z}\right)^{2}+\left(\frac{\partial U}{\partial y}+\frac{\partial V}{\partial x}\right)^{2} \\
+\left(\frac{\partial V}{\partial z}+\frac{\partial W}{\partial y}\right)^{2}+\left(\frac{\partial W}{\partial x}+\frac{\partial U}{\partial z}\right)^{2}
\end{gathered}
$$

where $K$ is the consistency index and $n$ is the flow behavior index. Then, the Navier-Stokes equation is solved by a finite volume-based algorithm, and in order to save memory resources, the SIMPLE (Semi-Implicit Method for Pressure-Linked Equations) algorithm is used to solve the pressure-velocity coupling. The momentum and energy equations are solved with a second order up-wind scheme.

\subsection{Data Reduction}

Reynolds number of a channel flow with power law fluid $[23,24]$ is generally defined as:

$$
\operatorname{Re}=\frac{\rho U_{a v e}^{2-n} D_{h}^{n}}{K}
$$

where $U_{\text {ave }}$ is the averaged velocity of inlet section, $D_{h}$ is the hydraulic diameter.

The Prandtl number and Nusselt number are defined as [25]:

$$
\begin{gathered}
\operatorname{Pr}=\frac{C K}{\lambda}\left(\frac{U_{\text {ave }}}{D_{h}}\right)^{n-1} \\
N u=\frac{h D_{h}}{\lambda}
\end{gathered}
$$

where $C$ is the fluid specific heat, $\lambda$ is the fluid thermal conductivity, $h$ is the heat transfer coefficient and can be computed by:

$$
\begin{gathered}
h=\frac{q^{\prime \prime}}{\Delta T} \\
\Delta T=T_{w, a v e}-T_{f, a v e}
\end{gathered}
$$

where $q$ " represents the heat flux, and $T$ is the average temperature difference between the wall and the fluids, $T_{w, \text { ave }}$ is the wall mean temperature of all the external walls, $T_{f, a v e}$ is the average temperature in the whole fluid domain, which are defined as:

$$
T_{w, \text { ave }}=\frac{\int_{A} T_{w} d A}{\int_{A} d A}, T_{f, \text { ave }}=\frac{\int_{V} u T d V}{\int_{V} d V}
$$

In many cases, flow characteristics can be analysed by entropy generation [26,27] in which both friction and heat transfer are considered. For an internal flow with diameter $D$, heat flux $q^{\prime \prime}$, the volumetric rate of entropy generation which can be derived from $[28,29]$ :

$$
S^{\prime}=\frac{q^{\prime \prime} \pi D_{h}^{2}}{k T^{2} N u}+\frac{32 Q^{3}}{\pi^{2} \rho^{2} T} \frac{f}{D_{h}^{5}}=S_{T}^{\prime}+S_{F}^{\prime}
$$

In this research, $T$ is the reference temperature. As it can be seen from Equation (18), the total entropy generation rate is contributed by two parts, heat transfer and friction [30,31]. What's more, Nusselt number and friction factor which are influenced by flow control structures and working substances also play important roles in the entropy generation.

\subsection{Working Substances}

CMC aqueous solution, as described above, is a specific shear-thinning power-law fluid. In order to simplify the calculations, some approximations that have little effect on the results are adopted, such as density, specific heat and thermal conductivity are considered as constant. Table 1 lists the values of these constants [3]. While the dynamic viscosity is different, in general, it depends on the 
shear rate and fluid temperature, but in this study, the fluid temperature difference of the flow field is small and the potential effects of the temperature-dependent thermophysical properties can be ignored. The fluid dynamic viscosity is controlled by the non-Newtonian power law equation. Table 2 lists the values of $n$ and $K$ of CMC aqueous solutions at four concentrations [21] used in this study.

Table 1. Constant properties of CMC aqueous solutions [3].

\begin{tabular}{cc}
\hline Property & Value \\
\hline Density $(\rho)$ & $1000 / \mathrm{kg} \cdot \mathrm{m}^{-3}$ \\
Specific heat $\left(C_{p}\right)$ & $4100 / \mathrm{J} \cdot \mathrm{kg}^{-1} \cdot \mathrm{K}^{-1}$ \\
Thermal conductivity $(\lambda)$ & $0.7 / \mathrm{W} \cdot \mathrm{m}^{-1} \cdot \mathrm{K}^{-1}$ \\
\hline
\end{tabular}

Table 2. Flow parameters of CMC aqueous solutions [21].

\begin{tabular}{ccc}
\hline Concentration/ppm & $\boldsymbol{K} \times \mathbf{1 0}^{\mathbf{3}} \mathbf{P a} \cdot \mathbf{s}^{\boldsymbol{n}}$ & $\boldsymbol{n}$ \\
\hline 100 & 3.83 & 0.9512 \\
500 & 8.49 & 0.8229 \\
2000 & 27.92 & 0.7051 \\
4000 & 657.2 & 0.6161 \\
\hline
\end{tabular}

\subsection{Physical Model and Boundary Conditions}

Figure 1 schematically shows the physical model and computational domain of microchannel with flow control structure studied in this research. Because the flow is fully developed, only one periodic domain was considered with periodic boundary conditions applied at the inlet and outlet for the simulation. The coordinates $x, y$, and $z$ represent the stream-wise, normal, and span-wise direction, respectively. The original rectangular microchannel is $50 \mu \mathrm{m}$ (height) $\times 200 \mu \mathrm{m}$ (width) in cross-section, and the periodic length is $150 \mu \mathrm{m}$. The flow control structure is arranged on one wall of the microchannel. The flow is fully developed with a fluid bulk temperature of $300 \mathrm{~K}$, a uniform heat flux of $q^{\prime \prime}=5 \times 10^{5} \mathrm{~W} \cdot \mathrm{m}^{-2}$ and no-slip boundary conditions are specified at the external surfaces of the microchannel.

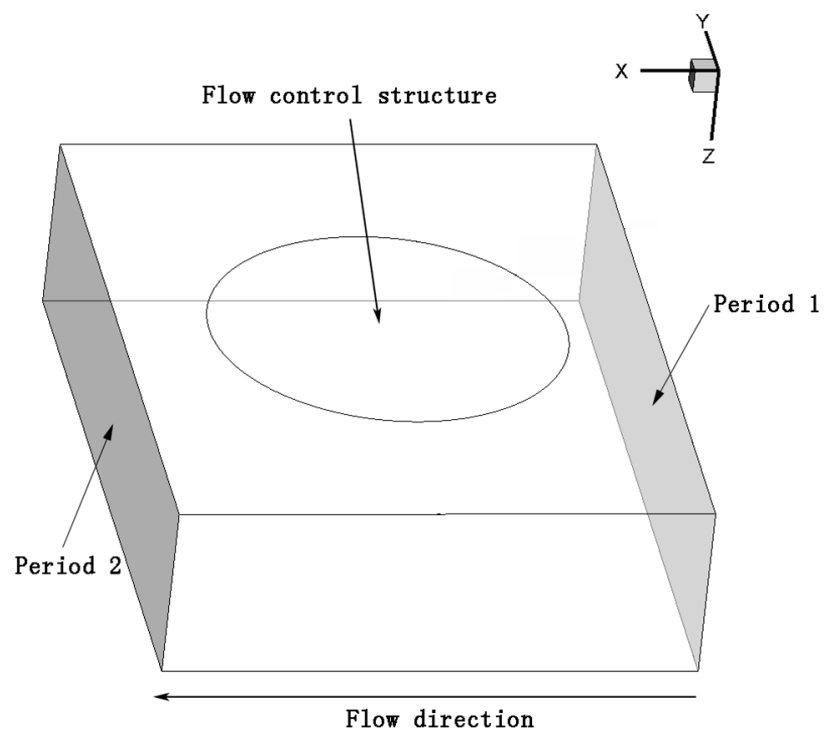

Figure 1. Schematic diagram of boundary conditions.

Figure 2 shows the four different flow control structures which all have a relative depth of $\delta / D=0.2$ adopted in this research. The four flow control structures also all have a printed diameter or 
width $D$ equaling $100 \mu \mathrm{m}$ on the corresponding wall. There are four different flow rates calculated in this study, which are $2 \times 10^{-5} \mathrm{~kg} \cdot \mathrm{s}^{-1}, 4 \times 10^{-5} \mathrm{~kg} \cdot \mathrm{s}^{-1}, 6 \times 10^{-5} \mathrm{~kg} \cdot \mathrm{s}^{-1}$, and $8 \times 10^{-5} \mathrm{~kg} \cdot \mathrm{s}^{-1}$.
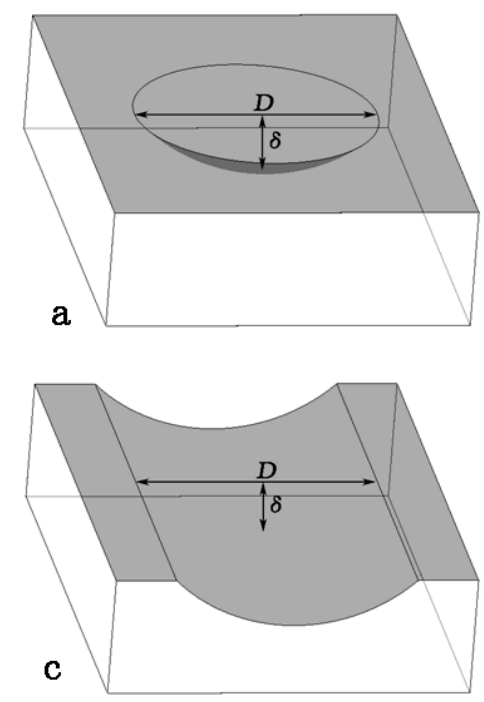

$\mathrm{b}$
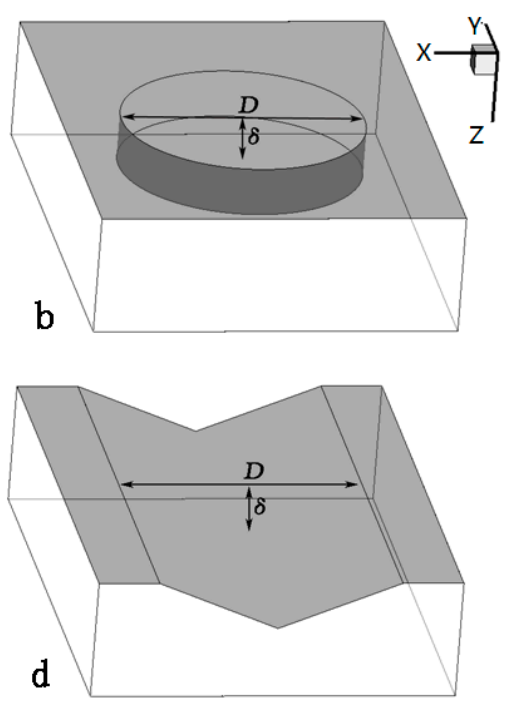

Figure 2. Geometrical structures of flow field: (a) protrusion; (b) pin fin; (c) cylinder rib; (d) V-groove.

\subsection{Model Validation}

Meshes that all have hexahedral elements are generated for the four different flow control structures and are refined in the near-wall region where the gradients of variables are very high. The grid independence validation is carried out by four different grid numbers of mesh. Finally, mesh with $1,608,960$ nodes, $1,568,336$ nodes, $1,622,400$ nodes, $1,519,600$ nodes are selected for the four different structures in the following study while the relative difference of $N u$ is lower than $0.8 \%$ and $f$ is lower than $0.5 \%$ at $\mathrm{CMC} 100$ and $Q=4 \times 10^{-5} \mathrm{~kg} \cdot \mathrm{s}^{-1}$. Table 3 shows the relative difference of $\mathrm{Nu}$ and $f$ between the four different meshes of protruded microchannel that employed in this research.

Table 3. Grid independence validation in the case of protruded microchannel at $Q=4 \times 10^{-5} \mathrm{~kg} / \mathrm{s}$ and CMC100.

\begin{tabular}{cccccc}
\hline & Nodes & $\mathbf{N u}$ & Difference $\%$ & $f$ & Difference $\%$ \\
\hline 1 & 387,840 & 5.617 & 2.831 & 0.0542 & 3.15 \\
2 & 794,880 & 5.776 & 1.143 & 0.0559 & 2.15 \\
3 & $1,160,493$ & 5.842 & 0.068 & 0.0571 & 0.35 \\
4 & $1,608,960$ & 5.846 & - & 0.0573 & - \\
\hline
\end{tabular}

\section{Results and Discussion}

\subsection{Flow Structures and Temperature Distribution}

In this paper, the detailed flow structures and temperature distribution are analyzed utilizing limiting streamlines and temperature contours on the walls with flow control structures, as well as the dynamic viscosity distribution and streamlines on the stream-wise and span-wise middle section.

The flow structures and temperature distribution in the microchannel with the four flow control structures are obviously different. Firstly, the temperature distribution and limiting streamlines of protrusion with different CMC concentrations at flow rate equaling $4 \times 10^{-5} \mathrm{~kg} \cdot \mathrm{s}^{-1}$ are shown in Figure 3. It can be easily found that the CMC concentration has some influence on the flow structures. In detail, flow separation occurs in the cases of CMC100, CMC500 and CMC2000, which means for cases with low CMC concentration, flow separates near the trailing edge of the protrusion 
and reattaches quickly, and also, when CMC concentration increases individually, the positions of separation and reattachment move along the anti-flow direction and flow direction, respectively, therefore, the separation bubble grows larger gradually (Figure 3a,b). As the CMC concentration increases further, flow slows down before it impinges on the wall in the front of protrusion, forming a separation bubble, and fluid separates at the tail of protrusion again when flow meet the re-circulated flow near the trailing edge of the protrusion, then the mixed flow reattached on the two sides of the flow direction (Figure 3c), the complex vortices effectively enhance the mass and heat transfer in the flow domain near the protruded wall, but the separation bubble is not observed in the flow domain in the cases of CMC4000, just leaving curved streamlines on the protruded walls, which is due to that the initial dynamic viscosity is so large that viscous force is relatively higher compared with the inertia force than that of most other fluids, so the vortices are not intense, which can also be observed in Figure 4. Furthermore, the temperature distribution is much different with each other among the four cases. The first three cases have a relatively uniform temperature distribution and the difference of maximum and minimum temperature is smaller than that of the last one, which is due to the flow separation and reattachment enhance the mixing of main flow and near-wall flow in the microchannel.
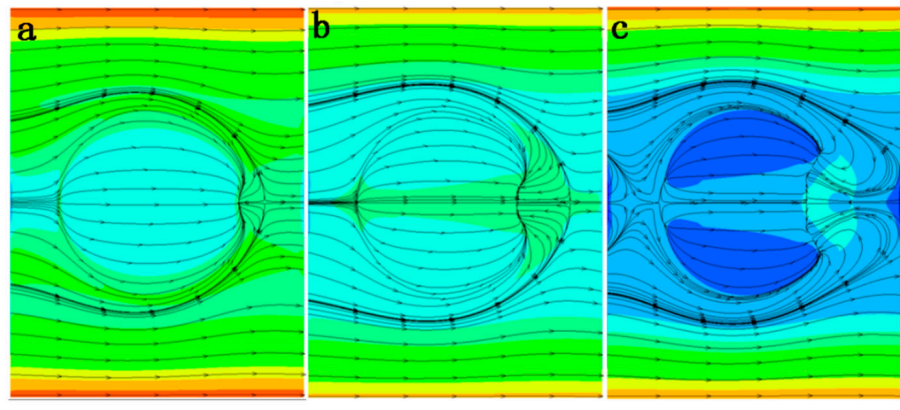

Temperature

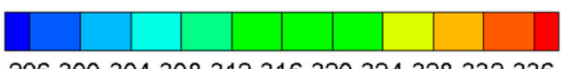

296300304308312316320324328332336
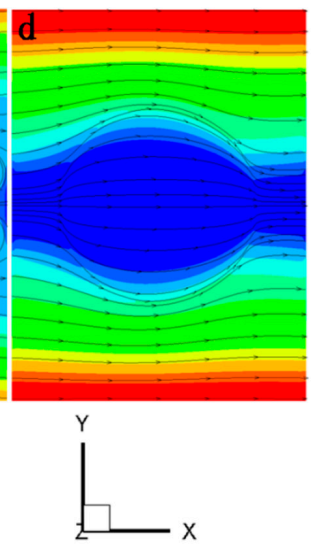

Figure 3. Temperature distributions (unit: $\mathrm{K}$ ) and limiting streamlines on the structured wall (Case: $Q=4 \times 10^{-5} \mathrm{~kg} \cdot \mathrm{s}^{-1}$ with protruded wall): (a) CMC100; (b) CMC500; (c) CMC2000; (d) CMC4000.
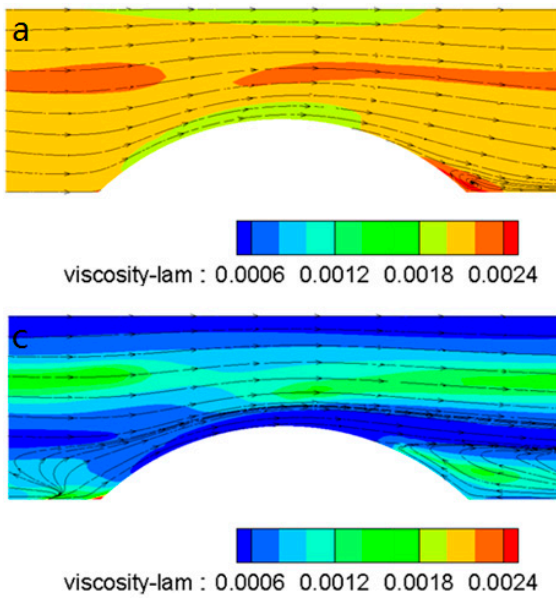

viscosity-lam : $0.0006 \quad 0.0012 \quad 0.0018 \quad 0.0024$

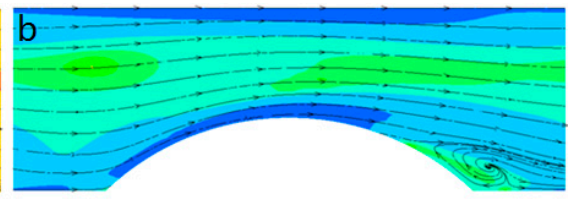

viscosity-lam : $0.0006 \quad 0.0012 \quad 0.0018 \quad 0.0024$

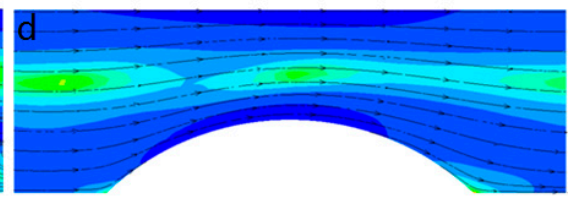

viscosity-lam : $0.004 \quad 0.01 \quad 0.016 \quad 0.022 \quad 0.028$

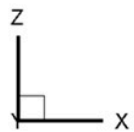

Figure 4. Dynamic viscosity distributions (unit: $\mathrm{Pa} \cdot \mathrm{s}$ ) and streamlines in the stream-wise middle sections (Case: $Q=4 \times 10^{-5} \mathrm{~kg} \cdot \mathrm{s}^{-1}$ with protruded wall): (a) CMC100; (b) CMC500; (c) CMC2000; (d) CMC4000. 
It must be noted that flow separation may not occur in some other cases with lower flow rate and lower CMC concentration, such as the case of CMC100 with flow rate equaling $4 \times 10^{-5} \mathrm{~kg} \cdot \mathrm{s}^{-1}$, the fluid flows slowly in the channel and can't stir up intense vortices in the fluid domain. The temperature gradient in these cases is relatively larger than that in the cases with separated flow, but smaller than the cases with large CMC concentration without separated flow such as Figure $3 \mathrm{~d}$. The temperature distribution is more uniform in the fluid domain when flow separation occurs, so combined with the above analysis, the CMC concentration could be adjusted to a proper value at which the separation occurs, namely, " $y$ " in the Table 4, to enhance the heat and mass transfer performance when flow rate and flow control structure are confirmed. As are shown in Table 4, separation flows in microchannel with protruded walls for all the cases are concluded and compared, in which " $\mathrm{n}$ " represents no separation flow, " $y$ " represents separation bubbles are observed in the flow domain.

Table 4. Flow separation modes near the protruded walls.

\begin{tabular}{ccccccccccccccccccc}
\hline Fluids & \multicolumn{1}{c}{ CMC100 } & \multicolumn{1}{c}{ CMC500 } & \multicolumn{1}{c}{ CMC2000 } & \multicolumn{3}{c}{ CMC4000 } \\
\hline $\mathrm{Q} \times 10^{5} / \mathrm{kg} \cdot \mathrm{s}^{-1}$ & 2 & 4 & 6 & 8 & 2 & 4 & 6 & 8 & 2 & 4 & 6 & 8 & 2 & 4 & 6 & 8 \\
protrusion & $\mathrm{n}$ & $\mathrm{y}$ & $\mathrm{y}$ & $\mathrm{y}$ & $\mathrm{y}$ & $\mathrm{y}$ & $\mathrm{y}$ & $\mathrm{y}$ & $\mathrm{y}$ & $\mathrm{y}$ & $\mathrm{y}$ & $\mathrm{y}$ & $\mathrm{n}$ & $\mathrm{n}$ & $\mathrm{n}$ & $\mathrm{y}$ \\
\hline
\end{tabular}

Figure 4 shows the dynamic viscosity distributions and streamlines on the stream-wise middle sections for the corresponding cases of Figure 3. They have the same legend except the last case in which the dynamic viscosity is much larger than that in the first three cases. It can be easily found that the dynamic viscosity decreases gradually when the CMC concentration increases from $100 \mathrm{ppm}$ to $2000 \mathrm{ppm}$ in the flow domain, and then has a sudden raise when CMC concentration further increases to $4000 \mathrm{ppm}$, which means the shear-thinning effect in the first three cases is so obviously that the effect of slowly increasing initial dynamic viscosity is suppressed, but in the last case, the initial dynamic viscosity increases to more than twenty times that of the CMC2000, which can be seen in Table 2, while $n$ decreases slowly as before, so the sharp increase of initial dynamic viscosity is more effective. Further, the combined results show that in the flow regions where dynamic viscosity is lower, the fluid velocity is relatively higher and the mass and heat transfer is more intense. So the wall-temperature near these regions is low. While in the regions where separation occurs, the temperature is higher than the temperature near flow reattachment regions (Figure 4a), which is because that the reattachment brings the center cold fluid to the region near the wall and produces higher heat transfer, but after the fluid chill down the heated wall, its temperature is relatively higher and then meet the fluid which are heated just by the upstream heating wall. Then, the mixed flow of the upstream and downstream separates from the wall in the separation region where the fluid flows from the hotter wall to colder core flowing, the small temperature difference can produce little heat transfer from the wall to the fluid. Moreover, from other cases that flow rate varies from $4 \times 10^{-5} \mathrm{~kg} \cdot \mathrm{s}^{-1}$ to $8 \times 10^{-5} \mathrm{~kg} \cdot \mathrm{s}^{-1}$ in the same concentration of CMC aqueous solution, it can be easily found that the separation bubble grows larger and wall temperature decreases gradually while the flow rate increases, which means the increase of the scale and intensity of separation bubble enhances the mixture of fluid between main flow and near-wall region, so the temperature of near-wall fluid decreases, and then the heat transfer between fluid and walls is improved, making the temperature of walls lower. What's more, in each case separately, the dynamic viscosity is lower in the regions near the up no-slip walls and in the front of the protrusion where fluid impinges on the protruded wall, the central plane of the flow domain has a higher dynamic viscosity. The flow separation region has the highest dynamic viscosity in the fluid domain, especially in the case of CMC100 (Figure 4a). The dynamic viscosity in the flow recirculation region is lower than the adjacent region (Figure 4c), which reflects the velocity gradient in the recirculation region is lower than the adjacent region where the flow direction is different, especially in the region near the tail of the protrusion. At last, it can be obviously observed that the separation bubble grows larger and larger as the CMC concentration increases in the first three cases, 
but disappears in the case of CMC4000 (Figure 4d) because of the high dynamic viscosity in the whole fluid domain.

Figure 5 shows the dynamic viscosity distributions and streamlines in the perpendicular to stream-wise middle sections for the corresponding cases of Figure 3. The intense complex three-dimensional flow feature of separation flow can be observed here. The flow vortices become flatter in this section as the concentration increase from $100 \mathrm{ppm}$ to $2000 \mathrm{ppm}$, so the flow vortices become more intense in the thin region near the structured wall. But the dynamic viscosity is so high that only two large gentle vortices are formed near the two side corner in this section and no separation occurs in this case of CMC4000. Further, it can be seen from each case individually that the main flow is compressed to both sides of the protrusion and generates $y$-direction and $z$-direction velocities around the protrusion, and then forms circular surface streamlines. The flow near the upper wall is also compressed to both sides of the protrusion and form two small recirculation region in the upper two corners. Moreover, the dynamic viscosity near the surrounding no-slip walls is the lowest in the whole flow domain because of the high shear stress in these regions except the two upper recirculation corners.

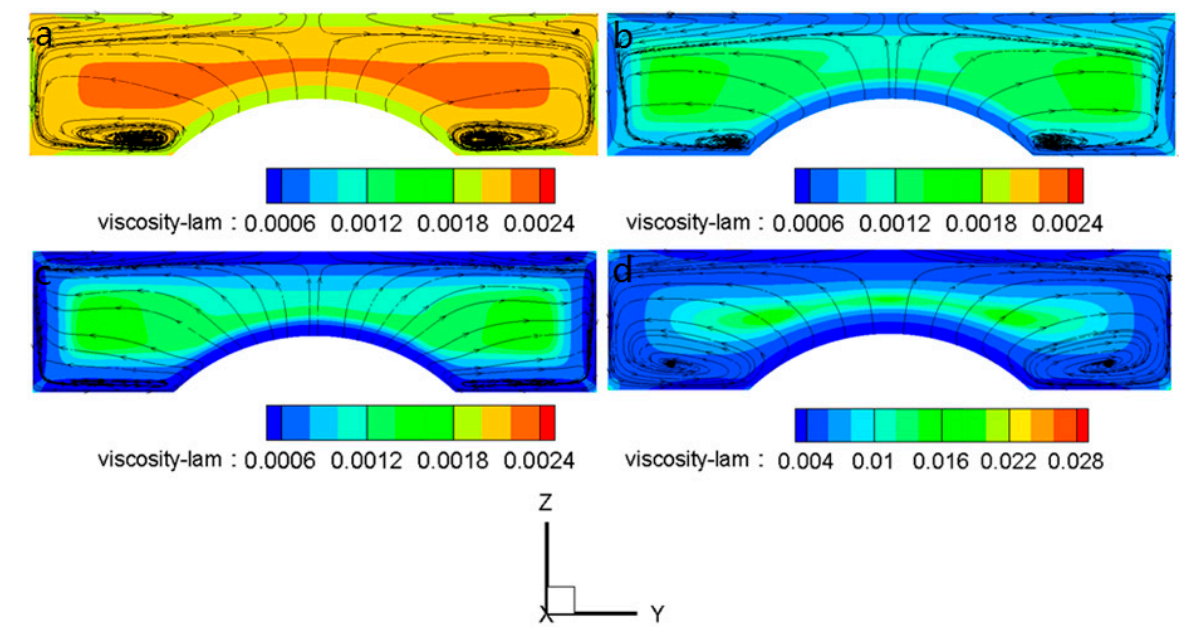

Figure 5. Dynamic viscosity distributions (unit: $\mathrm{Pa} \cdot \mathrm{s}$ ) and streamlines in the perpendicular to stream-wise middle sections (Case: $Q=4 \times 10^{-5} \mathrm{~kg} \cdot \mathrm{s}^{-1}$ with protruded wall): (a) CMC100; (b) CMC500; (c) CMC2000; (d) CMC4000.
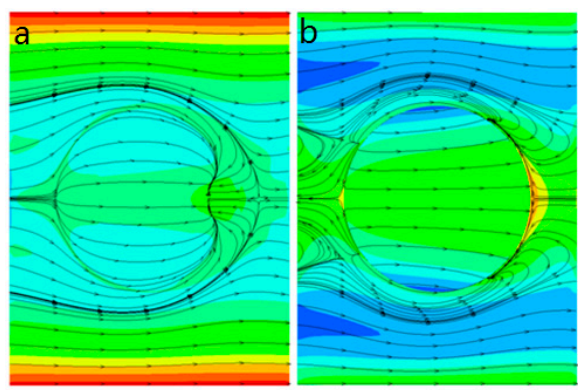

Temperature Dataset: 298301304307310313316319322325328
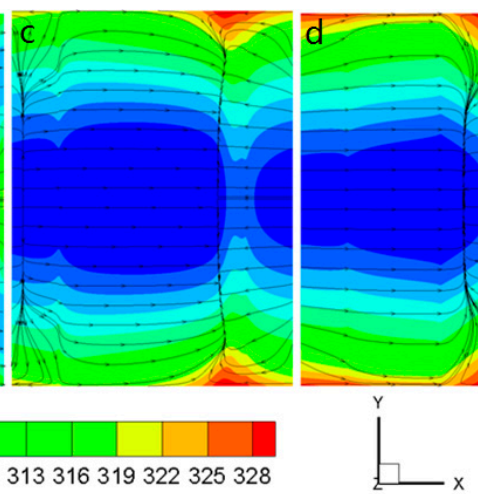

Figure 6. Temperature distributions (Unit: K) and limiting streamlines on structured wall (Case: $Q=2 \times 10^{-5} \mathrm{~kg} \cdot \mathrm{s}^{-1}$; CMC500): (a) protrusion; (b) pin-fin; (c) cylinder-rib; (d) V-groove.

Figure 6 shows the temperature distributions and limiting streamlines on the structured walls of microchannel with protrusions, pin-fins, cylinder-ribs, and V-grooves, respectively. The flow rate and $\mathrm{CMC}$ concentration are all the same in the four cases. Firstly, it can be easily found that the 
maximum temperature on the wall with pin-fin is obviously lower than that of the other structures; the average temperatures on the external walls for the four structures are $312.1 \mathrm{~K}, 309.8 \mathrm{~K}, 309.4 \mathrm{~K}$ and $311.5 \mathrm{~K}$, respectively, cylinder-rib has the minimum average temperature because of the large low temperature area near the center plane of span-wise direction. Further, the temperature gradient on pin-fin walls is the smallest in both the span-wise direction and the flow direction, so the pin-fin configuration has the most uniform temperature distribution at $Q=2 \times 10^{-5} \mathrm{~kg} \cdot \mathrm{s}^{-1}$ and CMC500 in the four different structures, which means heat transfer in the span-wise direction is much intense in the microchannel with pin-fin because of the non-uniform structure, in other words, the sudden change of the structure in the channel. Secondly, the flow structures in the microchannel with the four flow control structures are different from each other, the microchannel with pin-fins and protrusions change the flow structures greatly near the middle section of the span-wise direction, leaving curved limiting streamlines near the up and down no-slip walls, where the flow structure is little different from smooth rectangular microchannel. There is a recirculation region between two protrusions/pin-fins in the stream-wise direction, and the recirculation region almost fully fills the space between the two structures in pin-fin channel. Meanwhile, in the cylinder-rib channel, the separation bubbles almost fully cross the span-wise direction, and the difference of flow structures in span-wise direction is smaller than that of the first two cases, this cause a larger temperature gradient in this direction. Moreover, flow separates near the end of the cylinder-rib, and then reattaches in the front of next cylinder-rib, which is different from that in the V-groove channel in which the flow separates near and after the peak of the V-groove and reattaches quickly after the end of V-groove. The recirculation region in the V-groove channel is much smaller than that of the cylinder-rib channel in the flow direction. Thirdly, considering the temperature distribution near the sidewall of the microchannel, it can be found that the wall temperature near the downstream of the separation region is much higher than the temperature near the downstream of the reattachment region, which is consistent with the analysis of Figure 4 that wall temperature is higher near flow separation regions than that near reattachment regions.
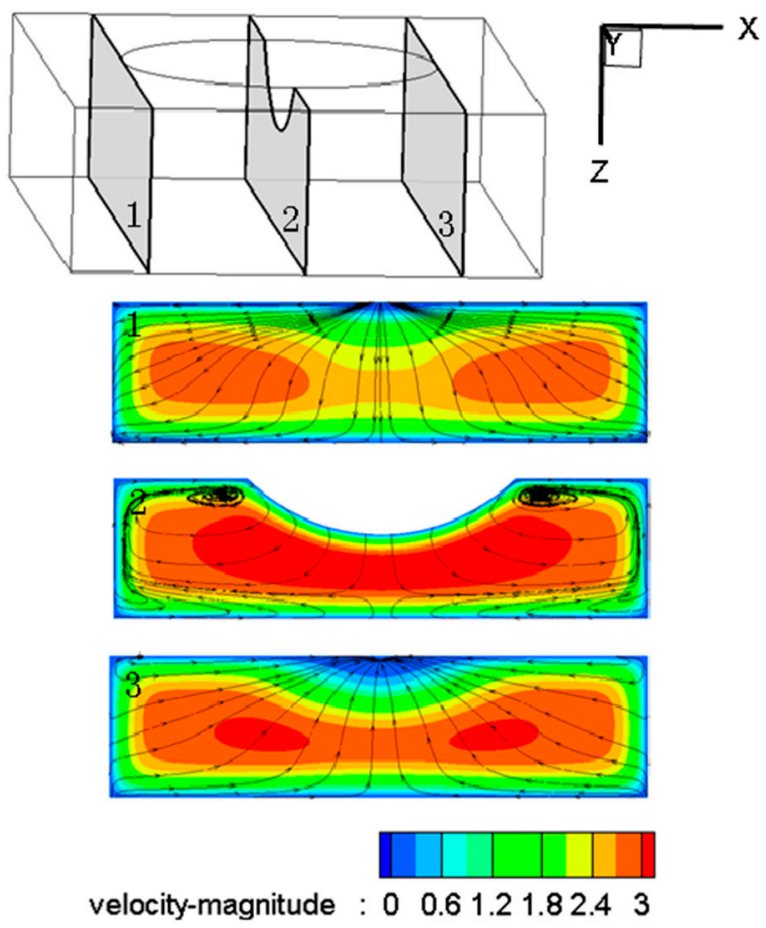

Figure 7. Velocity contours (unit: $\mathrm{m} \cdot \mathrm{s}^{-1}$ ) and streamlines in the perpendicular to stream-wise sections (Case: $Q=2 \times 10^{-5} \mathrm{~kg} \cdot \mathrm{s}^{-1}$; CMC500; protruded microchannel). 
Figure 7 shows the velocity magnitude distribution and streamlines in the three sections for the corresponding case of Figure 6a, the three sections are located in the front edge, the middle and the trailing edge of protrusion, respectively. It can be easily seen from the streamlines that the flow is compressed to both sides of the microchannel (section 1 in Figure 7) in the front of the protrusion, then forms two vortices on the two sides of protrusion (section 2 in Figure 7), at last, the fluid flows to the center of the microchannel near the trailing edge of the protrusion (section 3 in Figure 7). The highest velocity region is separated in the section 1 and section 3 while they are connected in section 2 because the section area is suppressed by the protrusion in this section. In the other corresponding cases of Figure $6 \mathrm{~b}-\mathrm{d}$, the fluid flows around the structured walls just like the case of Figure $6 \mathrm{a}$, but have more complicated vortex flow structures because of the large change of the sectional area in the flow direction.

In the other cases that have different flow rates $\left(2 \times 10^{-5}, 4 \times 10^{-5}, 6 \times 10^{-5}\right.$ and $\left.8 \times 10^{-5} \mathrm{~kg} \cdot \mathrm{s}^{-1}\right)$ and CMC concentrations (100, 500, 2000 and $4000 \mathrm{ppm}$ ) of the microchannel with the four different flow control structures, the laminar flow structures change little when compared with the cases mentioned above. The statistic data of heat and mass transfer of all the cases are analyzed in the following context.

\subsection{Flow Friction and Heat Transfer Performance Analysis}

To quantitatively evaluate the flow friction of shear-thinning power-law fluid in the microchannel with the four different flow control structures, the relative Fanning friction factor $f / f_{0}$ is comparative analyzed firstly, in which $f$ is defined as:

$$
f=-\frac{(\Delta p / L) D_{h}}{2 \rho U_{a v e}^{2}}
$$

where $\Delta p$ is the pressure drop and $L$ is the periodic length. The analytical solutions of baseline Fanning friction factor $f_{0}$ [32] for smooth rectangular microchannel with water as working substance are used to normalize the Fanning friction factor in this research, similar with our previous research [33], as the $L, D_{h}$, and $U_{\text {ave }}$ are all the same in each $f / f_{0}$, so:

$$
f / f_{0}=\Delta p / \Delta p_{0}
$$

where $\Delta p_{0}$ is the pressure drop of smooth rectangular microchannel with water as working substance. The value of $\Delta p_{0}$ is calculated and listed in the Table 5 , from which we can easily find that $\Delta p_{0}$ is proportional to flow rate.

Table 5. Pressure drop and Nusselt number of smooth rectangular microchannel with water as working substance.

\begin{tabular}{ccccc}
\hline Item & Case 1 & Case 2 & Case 3 & Case 4 \\
\hline$Q \times 10^{5} / \mathrm{kg} \cdot \mathrm{s}^{-1}$ & 2.0 & 4.0 & 6.0 & 8.0 \\
$\Delta p_{0} / \mathrm{Pa}$ & 1713 & 3436 & 5174 & 6930 \\
$N u_{0}$ & 4.30 & 4.33 & 4.35 & 4.38 \\
\hline
\end{tabular}

As is shown in Figures 8 and 9, the prefixes pro-, pin-, cyl-, and vgr- represent the microchannels with protrusion, pin-fin, cylinder-rib, and V-groove, respectively. $f / f_{0}$ doesn't similarly increase or decrease with the flow rate. The value of $f / f_{0}$ should be a constant if Newtonian fluid is chosen as working substance, but CMC aqueous solution is a typical shear-thinning power-law fluid, its dynamic viscosity decreases with the increase of shear strain rate, and a larger mass flow rate could produce a larger shear strain rate in the fluid domain (the volume-weighted average strain rates are 149,593, 298,824, 449,414 and 588,012 (unit: $\mathrm{s}^{-1}$ ) for cases of protrusion channel with CMC4000 at flow rate equaling $2 \times 10^{-5}, 4 \times 10^{-5}, 6 \times 10^{-5}$ and $8 \times 10^{-5}$ (unit: $\mathrm{kg} \cdot \mathrm{s}^{-1}$ ), respectively), so this can cause lower dynamic viscosity in some flow regions, lower dynamic viscosity needs less pressure drop to 
drive the fluid to flow in the microchannel, and then cause the $f / f_{0}$ is smaller than that of Newtonian fluid, the final result is $f / f_{0}$ decreases with the increase of flow rate. This trend is more obvious in these cases of CMC4000 in all microchannel with different flow control structures, because of the lower power of the exponential function of the viscosity, as Equation (8) shows. In some other cases such as CMC500 and CMC2000 in V-grooved microchannels (Figure 9), the value of $f / f_{0}$ increases with the increase of flow rate, which is mainly due to the initial dynamic viscosity and shear-thinning behavior of CMC aqueous solutions (Table 2) and separation flow induced by flow control structures on the walls. On the other hand, the flow control structure has great impact on the relationship between $f / f_{0}$ and flow rate, which is because that the flow separations in microchannel with the four flow control structures are quite different. Moreover, the value of $f / f_{0}$ decreases with the increase of the concentration of CMC solution firstly, after reach a minimum point, and then increases with the concentration, which means there is a minimum value of $f / f_{0}$ when varying the concentration of the CMC aqueous solution, the concentration is $2000 \mathrm{ppm}$ in all the cases of different flow rate and different flow control structures in this research.

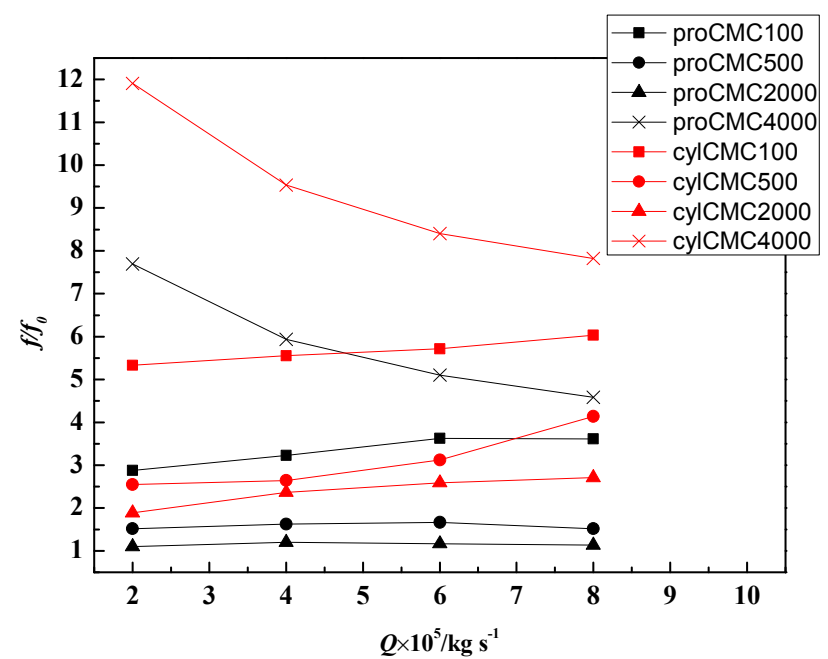

Figure 8. Variations of $f / f_{0}$ with flow rate and CMC concentration in protruded and cylinderribbed microchannels.

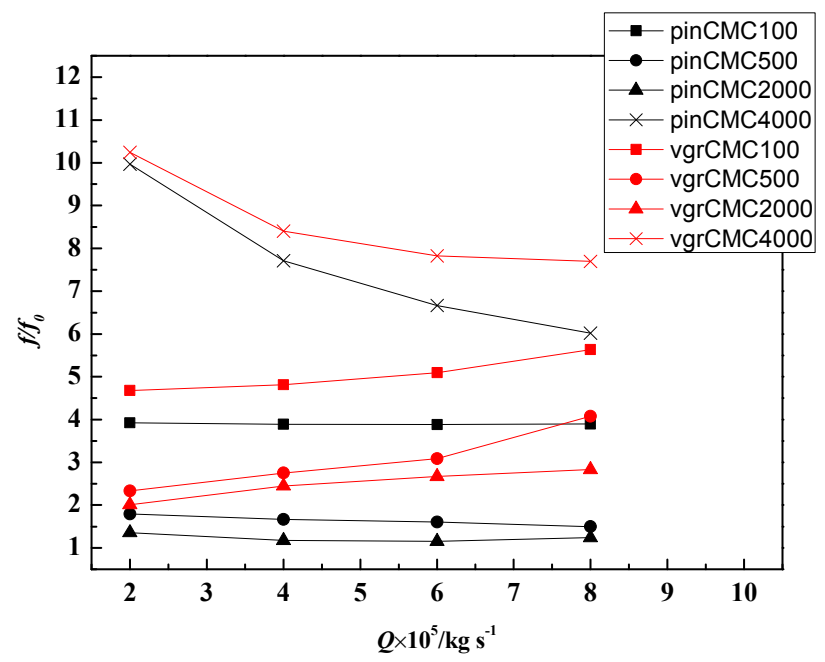

Figure 9. Variations of $f / f_{0}$ with flow rate and CMC concentration in pin-finned and V-grooved microchannels. 
The heat transfer performance can be reasonably analyzed by means of Nusselt number. The value of $N u / N u_{0}$ is obtained and showed in Figures 10 and 11, in which $N u_{0}$ is the Nusselt number of smooth rectangular microchannel with water as working substance. $N u / N u_{0}$ continuously increases with the increases of flow rate. The microchannel with protrusion has the minimum value of $N u / N u_{0}$ in the four flow control structures. What's more, $N u / N u_{0}$ increases as $\mathrm{CMC}$ concentration increases from $100 \mathrm{ppm}$ to $2000 \mathrm{ppm}$, which is because of the more intense separation flow caused by the more obvious shear-thinning effect. As CMC concentration further increases to $4000 \mathrm{ppm}$, larger dynamic viscosity fluid forms thicker thermal boundary layer, then streamlines just curves at most cases in protruded microchannels, at last, a minimum value is obtained at the CMC concentration equaling $4000 \mathrm{ppm}$, so the minimum $\mathrm{Nu} / \mathrm{N} u_{0}$ are reached in the case of proCMC4000 at $Q=2 \times 10^{-5} \mathrm{~kg} \cdot \mathrm{s}^{-1}$ (Figure 10), which is slightly different from that of the case vgrCMC4000 at $Q=2 \times 10^{-5} \mathrm{~kg} \cdot \mathrm{s}^{-1}$ (Figure 11). Moreover, in the cases of CMC500, the $N u / N u_{0}$ of V-groove microchannel at $Q=2 \times 10^{-5} \mathrm{~kg} \cdot \mathrm{s}^{-1}$ is much lower than the other cases, which is because no separation bubble forms in the flow domain and the heat quantity transferred in span-wise direction and flow direction are both very small, while in the other cases, such as in the cylinder-rib microchannel, flow separation bubbles are more easily to form because the greater sudden change of structured wall, so the heat transfer is enhanced, and in the pin-fin microchannel, the heat transferred in both the span-wise direction and flow direction is larger. The variation of $N u / N u_{0}$ is decided by the $\mathrm{CMC}$ concentration, flow rate and flow control structure. For cases in Figure $3 a-c, N u / N u_{0}$ is enlarged by separation flow due to the enhanced heat transfer between near-wall fluid and main fluid, while the last case in Figure 3 has no separation flow observed in the domain, and the structure of thermal boundary is not destroyed, which results in a small temperature gradient on the protruded wall, then the $N u / N u_{0}$ is smallest in the four cases.

What's more, it can be easily found that the $\mathrm{Nu} / \mathrm{Nu} u_{0}$ increases more quickly with the increases of flow rate in V-grooved channel than that in pin-finned and protruded channels, so it can be predicted that in lower flow rate cases, pin-fin and protrusion should have better heat transfer characteristics, which can also be seen from the thermal performance TP from the following context. Moreover, cylinder-ribbed and V-grooved microchannel has larger $N u / N u_{0}$ in large flow rate confirms the conclusion in Li's research [21] that the microchannels with cylinder and V-groove have better heat transfer performance compared with the protruded microchannel, especially at larger Re cases.

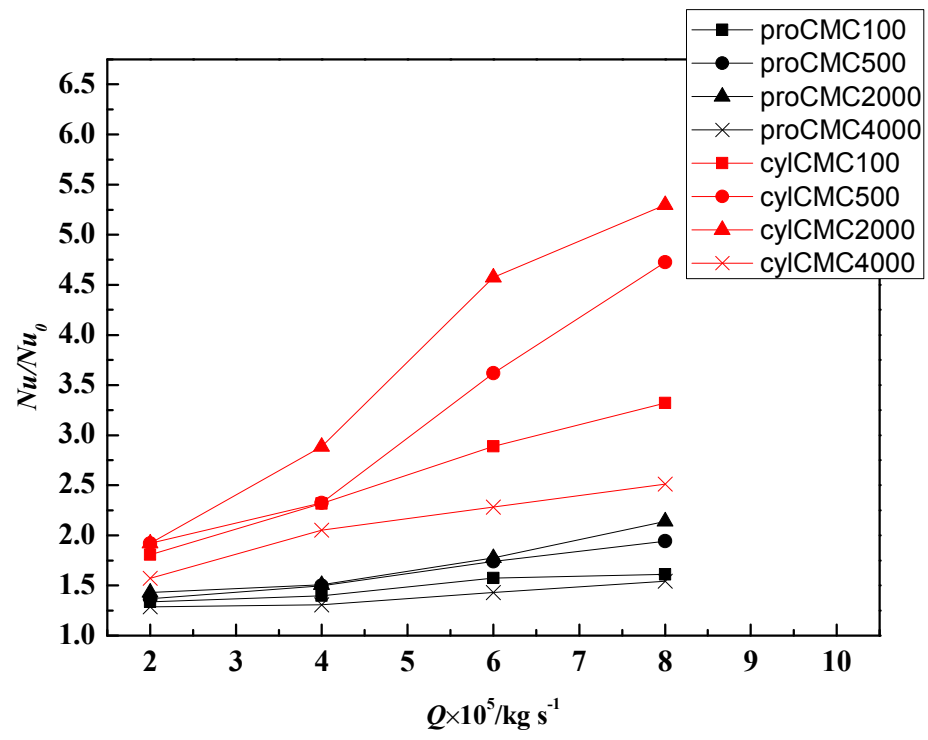

Figure 10. Variations of $N u / N u_{0}$ with flow rate and $\mathrm{CMC}$ concentration in protruded and cylinder-ribbed microchannels. 


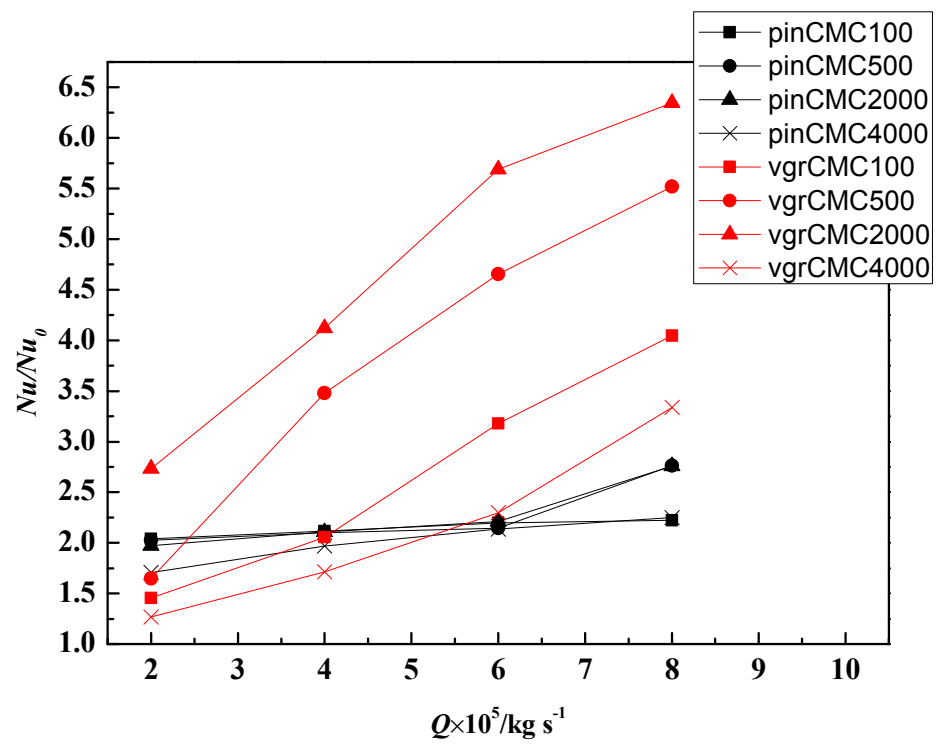

Figure 11. Variations of $N u / N u_{0}$ with flow rate and $\mathrm{CMC}$ concentration in pin-finned and V-grooved microchannels.

Figures 12 and 13 show the variation of relative entropy generation of the structured microchannel based on the Equation (17) which are normalized similar as the above parameters. It can be seen that $S^{\prime} / S_{0}{ }^{\prime}$ decreases with the increase of the flow rate in all the cases. While in the pin-finned microchannels, the decreasing trend is not obvious as in the other microchannels, which is mainly because that entropy generation contributed by Nusselt number is much larger than the friction factor in these cases, especially at low flow rates. The ratio of $S_{F}{ }^{\prime} / S_{T}{ }^{\prime}$ is smaller than 0.121 in all the pin-finned cases, and its average value is 0.046 in all the cases. Therefore, the entropy generation is dominant by the part of Nusselt number and slightly influenced by friction factor. In low flow rate, $S^{\prime} / S_{0}{ }^{\prime}$ are relatively large in pin-finned microchannel compared with other cases. Protruded microchannel always has large $S^{\prime} / S_{0}{ }^{\prime}$ because of the poor heat transfer performance. The smallest $S^{\prime} / S_{0}{ }^{\prime}$ is reached in the V-grooved microchannel at CMC2000, so V-grooved microchannel at CMC2000 has favorable entropy generation performance, which is consistent with the result of TP that are showed below.

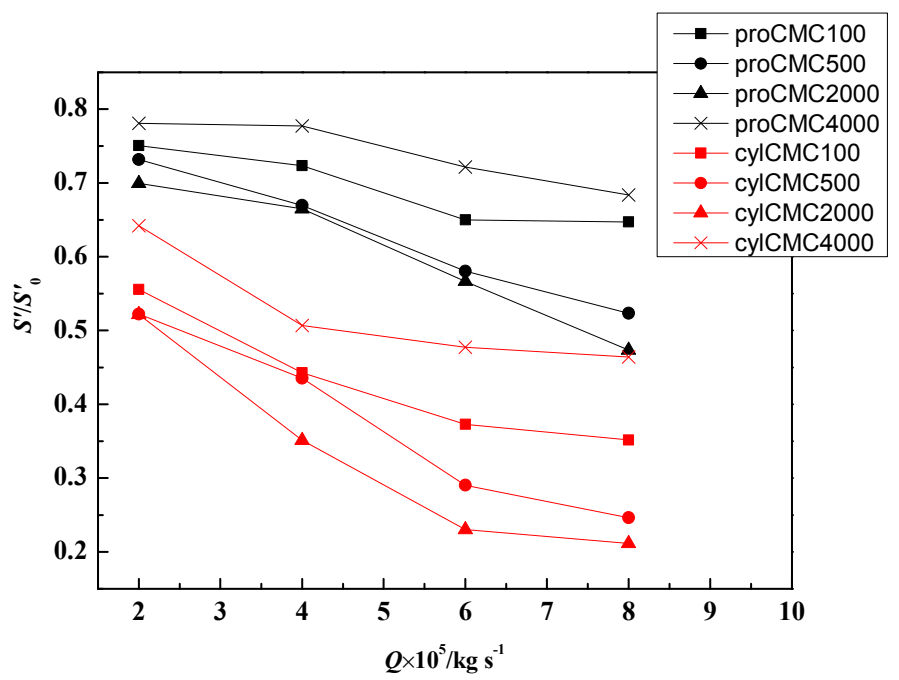

Figure 12. Variations of $S^{\prime} / S_{0}^{\prime}$ with flow rate and CMC concentration in protruded and cylinder-ribbed microchannels. 


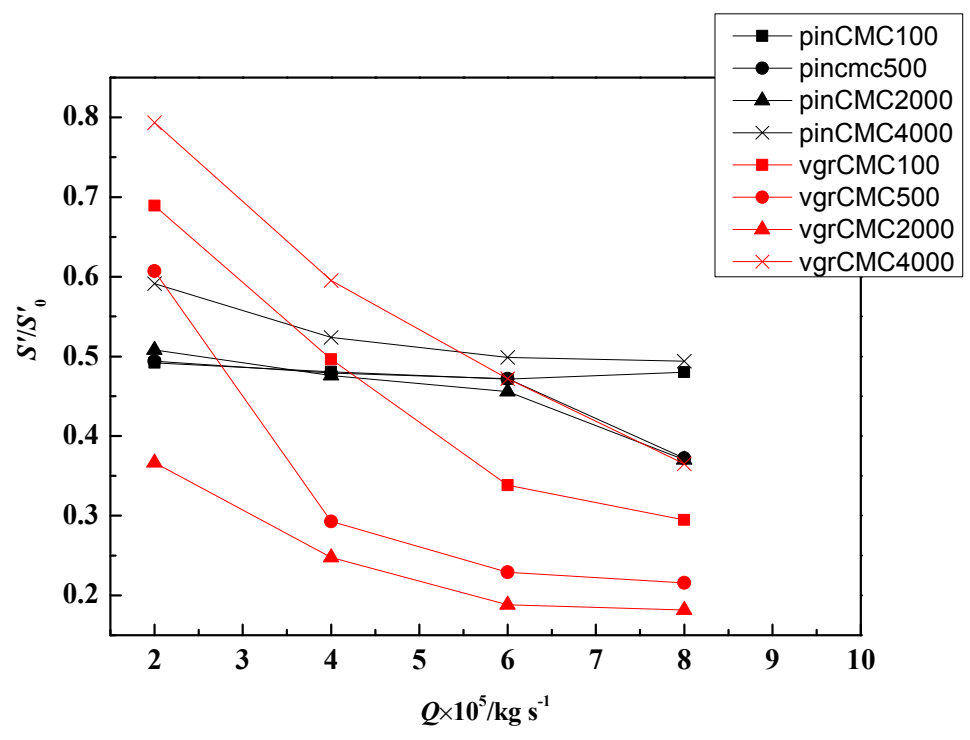

Figure 13. Variations of $S^{\prime} / S_{0}^{\prime}$ with flow rate and CMC concentration in pin-finned and V-grooved microchannels.

The whole thermal performance TP considers both the heat transfer and friction resistance, which is described as:

$$
T P=\left(\frac{N u}{N u_{0}}\right) \cdot\left(\frac{f}{f_{0}}\right)^{-1 / 3}
$$

The variation of TP for different cases is shown in Figures 14 and 15. TP has a similar trend with $\mathrm{Nu} / \mathrm{Nu}_{0}$ when flow rate and CMC concentration increases. In cases of vgrCMC500 (Figure 15), TP grows faster when flow rate increases from $2 \times 10^{-5} \mathrm{~kg} \cdot \mathrm{s}^{-1}$ to $4 \times 10^{-5} \mathrm{~kg} \cdot \mathrm{s}^{-1}$, which is because not only the vortices become more intense, but also more complex flow vortices are generated in the flow domain, when the flow rate further increases to $8 \times 10^{-5} \mathrm{~kg} \cdot \mathrm{s}^{-1}$, the structure of the vortices keep the same but only become more intense. In cases of cylCMC500 and cylCMC2000 (Figure 14), this change delayed and comes when flow rate increases from $4 \times 10^{-5} \mathrm{~kg} \cdot \mathrm{s}^{-1}$ to $6 \times 10^{-5} \mathrm{~kg} \cdot \mathrm{s}^{-1}$. Similar to this, the TP in cases of vgrCMC2000 and cylCMC2000 increases more slowly when the flow rate increases from $6 \times 10^{-5} \mathrm{~kg} \cdot \mathrm{s}^{-1}$ to $8 \times 10^{-5} \mathrm{~kg} \cdot \mathrm{s}^{-1}$, which is because no more vortex forms in the flow domain but only the existing vortices become more intense.

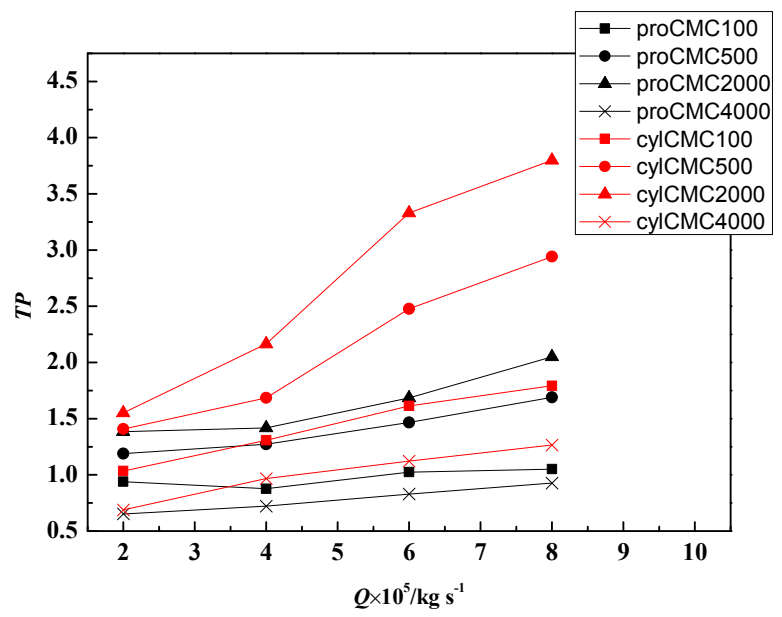

Figure 14. Variations of $T P$ with flow rate and $C M C$ concentration in protruded and cylinder-ribbed microchannels. 


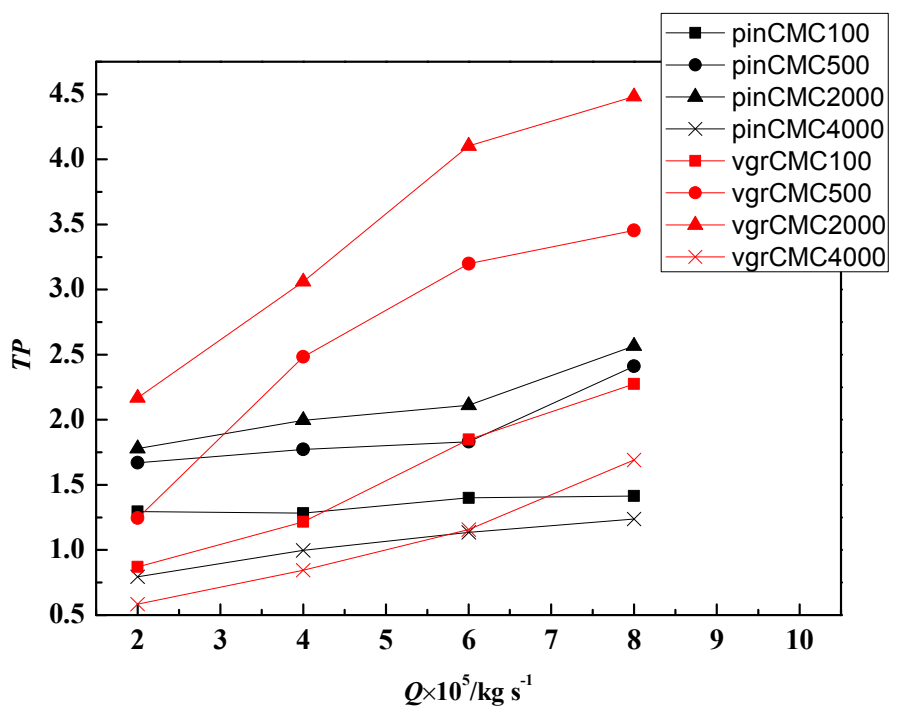

Figure 15. Variations of $T P$ with flow rate and CMC concentration in pin-finned and V-grooved microchannels.

It should be noted that TP in the microchannel with cylinder-rib and V-groove increases faster than that in the other two microchannels, because the flow vortices in the pin-finned and protruded microchannel is small and the section area in the stream-wise direction are not changed so large as the cylinder-rib and V-groove channel, which can cause much larger vortices in the fluid domain that almost fully fill the span-wise direction. In the cases of flow rate smaller than or equals to $2 \times 10^{-5} \mathrm{~kg} / \mathrm{s}$, pin-finned microchannel has the largest TP and is the best flow control structures in the four microchannels. The largest TP is reached in V-grooved microchannel at CMC2000 and the smallest is in protruded microchannel at CMC4000 when flow rate is larger than $2 \times 10^{-5} \mathrm{~kg} \cdot \mathrm{s}^{-1}$. But considering the cost and benefit, the $f / f_{0}$ and $N u / N u_{0}$ are larger at some cases, resulting in a relative larger $T P$, however, which are not suitable for practical applications with limited pressure drops between inlet and outlet, so the selection of working conditions should also consider the practical conditions.

\section{Conclusions}

In this research, non-Newtonian laminar flow in microchannels with four flow control structures are studied, and then optimized flow control structures with special CMC concentration in different cases are obtained, which can be concluded as the follows:

(1) The pin-fin microchannel has the most uniform temperature distribution on the structured walls and the area-average temperature of the pin-finned wall reaches the lowest point in the four different flow control structures at different $\mathrm{CMC}$ concentrations when the flow rate equals $2 \times 10^{-5} \mathrm{~kg} / \mathrm{s}$. What's more, as the flow rate further decreases, pin-finned microchannel should have the largest TP in the four flow control structures and is preferred to be selected.

(2) The microchannel with protrusion has the minimum relative Fanning friction factor $f / f_{0}$ that just slightly larger than smoothing rectangular microchannel with water, but $N u / N u_{0}$ increases up to 2 in these cases, so protrusion can be selected if the pressure drops are strictly limited in some cases. And also, the protrusion is preferred to be selected in low flow rate cases.

(3) The V-groove microchannel has the minimum $S^{\prime} / S_{0}{ }^{\prime}$ and maximum $T P$ when flow rates larger than $2 \times 10^{-5} \mathrm{~kg} / \mathrm{s}$ at different CMC concentrations, and can be selected in some cases need large heat removal with high flow rate and pressure drop. 
(4) The relative Fanning friction factor $f / f_{0}$ has a minimum value when the CMC concentration increases and the minimum value of $f / f_{0}$ is reached at CMC2000 in this study, and also, the $\mathrm{Nu} / \mathrm{Nu} u_{0}$ of CMC2000 cases is larger than that of other working substances in the four different structured microchannels. Combined with these two effects, $2000 \mathrm{ppm}$ is the best CMC concentration in the four different microchannel and has both minimum $f / f_{0}$ and maximum $N u / N u_{0}$, and then minimum $S^{\prime} / S_{0}{ }^{\prime}$ and highest $T P$.

Author Contributions: Ke Yang and Di Zhang performed the numerical simulations, finished the result analysis. Yonghui Xie and Gongnan Xie wrote the manuscript. All authors contributed equally for reviewing and revising the manuscript. All authors have read and approved the final manuscript.

Conflicts of Interest: The authors declare no conflict of interest.

\section{Abbreviations}

The following abbreviations are used in this manuscript:

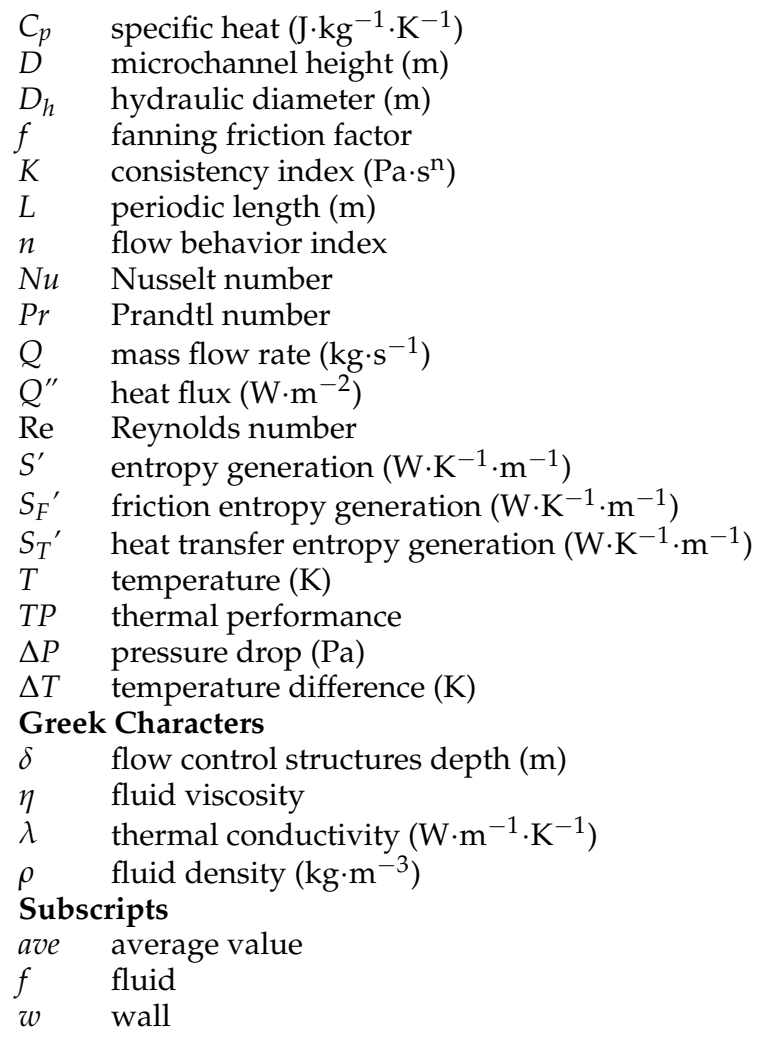

\section{References}

1. Kandlikar, S.; Garimella, S.; Li, D.; Colin, S.; King, M.R. Heat Transfer and Fluid Flow in Minichannels and Microchannels; Elsevier: Amsterdam, The Netherlands, 2005.

2. Zhang, D.; Zheng, L.; Xie, G.; Xie, Y. An experimental study on heat transfer enhancement of non-newtonian fluid in a rectangular channel with dimples/protrusions. J. Electron. Packag. 2014, 136, 021005. [CrossRef]

3. Li, P.; Xie, Y.; Zhang, D. Laminar flow and forced convective heat transfer of shear-thinning power-law fluids in dimpled and protruded microchannels. Int. J. Heat Mass Transf. 2016, 99, 372-382. [CrossRef]

4. Naphon, P.; Kornkumjayrit, K. Numerical analysis on the fluid flow and heat transfer in the channel with V-shaped wavy lower plate. Int. Commun. Heat Mass Transf. 2008, 35, 839-843. [CrossRef]

5. Yang, Y.-T.; Peng, H.-S. Numerical study of pin-fin heat sink with un-uniform fin height design. Int. J. Heat Mass Transf. 2008, 51, 4788-4796. [CrossRef]

6. Liu, M.; Liu, D.; Xu, S.; Chen, Y. Experimental study on liquid flow and heat transfer in micro square pin fin heat sink. Int. J. Heat Mass Transf. 2011, 54, 5602-5611. [CrossRef] 
7. Huang, C.-H.; Chen, Y.-H. An impingement heat sink module design problem in determining simultaneously the optimal non-uniform fin widths and heights. Int. J. Heat Mass Transf. 2014, 73, 627-633. [CrossRef]

8. Mamourian, M.; Shirvan, K.M.; Ellahi, R.; Rahimi, A.B. Optimization of mixed convection heat transfer with entropy generation in a wavy surface square lid-driven cavity by means of Taguchi approach. Int. J. Heat Mass Transf. 2016, 102, 544-554. [CrossRef]

9. Gong, L.; Kota, K.; Tao, W.; Joshi, Y. Parametric numerical study of flow and heat transfer in microchannels with wavy walls. J. Heat Transf. 2011, 133, 051702. [CrossRef]

10. Gong, L.J.; Kota, K.; Tao, W.; Joshi, Y. Thermal performance of microchannels with wavy walls for electronics cooling. IEEE Trans. Compon. Packag. Manuf. Technol. 2011, 1, 1029-1035. [CrossRef]

11. Xie, Y.; Zhang, Z.; Shen, Z.; Zhang, D. Numerical Investigation of Non-Newtonian Flow and Heat Transfer Characteristics in Rectangular Tubes with Protrusions. Math. Probl. Eng. 2015, 2015, 121048. [CrossRef]

12. Roth, R.; Lenk, G.; Cobry, K.; Woias, P. Heat transfer in freestanding microchannels with in-line and staggered pin fin structures with clearance. Int. J. Heat Mass Transf. 2013, 67, 1-15. [CrossRef]

13. Li, Y.; Wang, X.; Yuan, S.; Tan, S.K. Flow development in curved rectangular ducts with continuously varying curvature. Exp. Therm. Fluid Sci. 2016, 75. [CrossRef]

14. Ellahi, R.; Aziz, S.; Zeeshan, A.; Ellahi, R.; Aziz, S. Non-newtonian nanofluid flow through a porous medium between two coaxial cylinders with heat transfer and variable viscosity. J. Porous Media 2013, 16, 205-216. [CrossRef]

15. Barkhordari, M.; Etemad, S.G. Numerical study of slip flow heat transfer of non-Newtonian fluids in circular microchannels. Int. J. Heat Fluid Flow 2007, 28, 1027-1033. [CrossRef]

16. Peixinho, J.; Desaubry, C.; Lebouche, M. Heat transfer of a non-Newtonian fluid (Carbopol aqueous solution) in transitional pipe flow. Int. J. Heat Mass Transf. 2008, 51, 198-209. [CrossRef]

17. Ternik, P. Planar sudden symmetric expansion flows and bifurcation phenomena of purely viscous shear-thinning fluids. J. Non-Newton. Fluid Mech. 2009, 157, 15-25. [CrossRef]

18. Manica, R.; De Bortoli, A. Simulation of sudden expansion flows for power-law fluids. J. Non-Newton. Fluid Mech. 2004, 121, 35-40. [CrossRef]

19. Ellahi, R.; Shivanian, E.; Abbasbandy, S.; Hayat, T. Numerical study of magnetohydrodynamics generalized Couette flow of Eyring-Powell fluid with heat transfer and slip condition. Int. J. Numer. Methods Heat Fluid Flow 2016, 26, 1433-1445. [CrossRef]

20. Ellahi, R.; Rahman, S.U.; Gulzar, M.M.; Nadeem, S.; Vafai, K. A Mathematical Study of Non-Newtonian Micropolar Fluid in Arterial Blood Flow Through Composite Stenosis. Appl. Math. Inf. Sci. 2014, 8, 1567-1573. [CrossRef]

21. Ellahi, R. The effects of MHD and temperature dependent viscosity on the flow of non-Newtonian nanofluid in a pipe. Appl. Math. Model. 2013, 37, 1451-1467. [CrossRef]

22. Nitiapiruk, P.; Mahian, O. Performance characteristics of a microchannel heat sink using $\mathrm{TiO}_{2} /$ water nanofluid and different thermophysical models. Int. Commun. Heat Mass Transf. 2013, 47, 98-104. [CrossRef]

23. Nejat, A.; Mirzakhalili, E.; Aliakbari, A.; Niasar, M.S.F.; Vahidkhah, K. Non-Newtonian power-law fluid flow and heat transfer computation across a pair of confined elliptical cylinders in the line array. J. Non-Newton. Fluid Mech. 2012, 171, 67-82. [CrossRef]

24. Soares, A.; Ferreira, J.; Chhabra, R. Flow and forced convection heat transfer in crossflow of non-Newtonian fluids over a circular cylinder. Ind. Eng. Chem. Res. 2005, 44, 5815-5827. [CrossRef]

25. Xie, Y.; Zheng, L.; Zhang, D.; Xie, G. Entropy Generation and Heat Transfer Performances of $\mathrm{Al}_{2} \mathrm{O}_{3}-\mathrm{Water}$ Nanofluid Transitional Flow in Rectangular Channels with Dimples and Protrusions. Entropy 2016, 18, 148. [CrossRef]

26. Ellahi, R.; Hassan, M.; Zeeshan, A. Shape effects of nanosize particles in $\mathrm{Cu}-\mathrm{H}_{2} \mathrm{O}$ nanofluid on entropy generation. Int. J. Heat Mass Transf. 2015, 81, 449-456. [CrossRef]

27. Akbar, N.S.; Raza, M.; Ellahi, R. Endoscopic Effects with Entropy Generation Analysis in Peristalsis for the Thermal Conductivity of $\mathrm{H}_{2} \mathrm{O}+\mathrm{Cu}$ Nanofluid. J. Appl. Fluid Mech. 2016, 9, 1721-1730.

28. Bejan, A. A study of entropy generation in fundamental convective heat transfer. J. Heat Transf. 1979, 101, 718-725. [CrossRef]

29. Li, P.; Xie, Y.; Zhang, D.; Xie, G. Heat Transfer Enhancement and Entropy Generation of Nanofluids Laminar Convection in Microchannels with Flow Control Devices. Entropy 2016, 18, 134. [CrossRef] 
30. Ellahi, R.; Hassan, M.; Zeeshan, A.; Khan, A.A. The shape effects of nanoparticles suspended in HFE-7100 over wedge with entropy generation and mixed convection. Appl. Nanosci. 2016, 6, 641-651. [CrossRef]

31. Akbar, N.S.; Raza, M.; Ellahi, R. Peristaltic flow with thermal conductivity of $\mathrm{H}_{2} \mathrm{O}+\mathrm{Cu}$ nanofluid and entropy generation. Results Phys. 2015, 5, 115-124. [CrossRef]

32. Shah, R.K.; London, A.L. Laminar Flow Forced Convection in Ducts: A Source Book for Compact Heat Exchanger Analytical Data; Academic Press: Cambridge, MA, USA, 2014.

33. Li, P.; Zhang, D.; Xie, Y. Heat transfer and flow analysis of $\mathrm{Al}_{2} \mathrm{O}_{3}$-water nanofluids in microchannel with dimple and protrusion. Int. J. Heat Mass Transf. 2014, 73, 456-467. [CrossRef]

(C) 2016 by the authors; licensee MDPI, Basel, Switzerland. This article is an open access article distributed under the terms and conditions of the Creative Commons Attribution (CC-BY) license (http://creativecommons.org/licenses/by/4.0/). 